\title{
Learning objectives for teaching and training
}

\section{Patricia Hughes}

\begin{abstract}
"Everywhere increased complexity and mindburdening terminology. What is the teacher to do? And more important, what can the poor student do, confronted with so much new knowledge and a Rabelaisian onomatomania?"' (Osler, 1913).
\end{abstract}

The publication of Tomorrow's Doctors (General Medical Council, 1993) opened our minds to the need for a more thoughtful and evaluated approach to education in medicine. The expansion of medical knowledge has shown no sign of slowing, which makes it imperative that we find ways to prioritise and organise what we teach so that students are given a clear structure. Learning objectives are one of the building blocks that give order to what we do with and for our students.

Learning objectives are statements of what students will be able or be expected to do after completing a course of study or training. Well-written, they allow clear communication from teachers to students, among teachers in an institution and between institutions. Importantly, they give students responsibility: tutors provide resources like lectures, course notes and tutorials, but students who know from the outset where they are going are encouraged to participate in their own learning.

A useful classification of learning objectives is: (a) knowledge objectives; (b) skills objectives; and (c) attitudinal objectives. Learning objectives are different from the goals or aims of a course (Box 1 ). The goals or aims are the broad intentions of what the course or the institution wants to achieve.

Writing learning objectives forces us to prioritise and to define essential information and skills. There is evidence that not giving students learning objectives leads to question-guessing and actually decreases the amount and thoroughness of learning (Prideaux, 1992; quoted by Lowry, 1993) (see Box 2).

\section{Learning objectives, the lesson plan and assessment}

If learning objectives are the place we are trying to get to, the lesson plan is the route we take, and assessment is how we know we have arrived. Good planning incorporates these from the start.

Planning teaching is done in logical steps: (a) What are the learning objectives (knowledge, skills and attitudes)?; (b) what will be the structure of the module?; (c) what will be the structure of each session?; and (d) how will the students be assessed?

\section{Box 1. Goals and learning objectives}

The goal of a clinical seminar is:

To introduce the students to the principles of community mental health care

The learning objectives state that by the end of the seminar the student will be able to:

Explain what is meant by a 'multi-disciplinary team'

Outline the role of different members of the multi-disciplinary team in a community mental health team

Discuss the roles of the general practitioner and community mental health team in the management of a patient with chronic schizophrenia

Patricia Hughes is Senior Lecturer in Psychotherapy and in Medical Education at St George's Hospital Medical School, London SW17 ORE. She teaches undergraduate psychiatry and runs courses on teaching skills for postgraduates. She helped draft the proposed psychotherapy learning objectives for the MRCPsych. Her research interest is the effect of stillbirth on parental mental health and the attachment of the next-born child. 
Box 2. Utility of learning objectives

Course organisers can encourage deep learning, i.e. understanding as well as rote learning (see below)

Students know what they need to learn to reach a desired level. They are less anxious

Teachers can coordinate their teaching across a course

Learning objectives act as a checklist for student learning

Assessment is fair and includes core knowledge and skills

For example, I am asked to teach undergraduate students about the role of the community mental health team. I have agreed the learning objectives with colleagues. These are public and the students know that the end-of-term assessment is always from the term's learning objectives. I must now think how students will effectively learn the material, so I need to decide the teaching methods and structure of the session:

- How much do the students already know?

- How many of them are there?

- How much time do I have?

- How can I construct a lively session which will cover the material and make them think for themselves?

- Should I give a lecture?

- Would a handout be more useful and efficient than a lecture?

I decide to begin with a clinical problem and get the students to work towards the learning objectives from a clinically relevant issue. I write a lesson plan for the one hour session (Box 3 ).

\section{What do we mean by 'the curriculum'?}

It has been suggested that both undergraduate and postgraduate medical courses have not one but at least three curricula (see Box 4) (Lowry, 1992):

- the stated curriculum - the published statement of what is included in the curriculum

- the taught curriculum - what is taught to the students during the course; and

- the assessed curriculum - what is evaluated at some point in the course.
Box 3. Lesson plan: seminar for 30 students on 'Introduction to the principles of Community Mental Health Care'

Give students the learning objectives and a clinical problem, e.g. 25-year- old man with chronic schizophrenia, cared for by the multi-disciplinary community team (may need details of multi-disciplinary team, clinical details).

Students work in groups of five, and brainstorm clinical issues; the role of different members of the team; and ways to communicate effectively with the general practitioner (15 minutes)

Students feed back their ideas to the whole group (10 minutes)

Tutor gives a short talk covering points raised, the clinical problem and management issues; students can take notes to answer the questions they have identified as important (20 minutes)

Students have time to ask questions or to raise points for discussion (10 minutes)

Tutor may suggest learning task, e.g. write answers to learning objectives as revision (5 minutes); give accessible references

The stated curriculum is in the form of learning objectives. It is a list of all the core knowledge, skills and attitudes we expect our students to acquire by the time they are allowed to qualify and proceed to practise as doctors or as specialists.

The assessed curriculum may be regarded as the true curriculum: it is what all students will learn, although some will also learn other things. It is immediately obvious that if an institution is to retain credibility as an examining body, the stated curriculum must at least include the assessed curriculum, and must not omit material which is to be examined.

There is a good argument that the taught curriculum might include material which is not examined, for example, a presentation by a distinguished researcher which stimulates interest in the subject and in research, but is clearly beyond the students' level of knowledge. Some learning will also be done independently by the students, without formal teaching.

\section{Approaches to learning}

The quality of a person's learning is very much influenced by motivation. 
Box 4. Stated, taught and examined curricula

Most courses have three curricula: the stated, the taught and the assessed

The assessed curriculum must lie within the stated curriculum

The taught curriculum may be slightly different. This should be explicit, especially for students who get very anxious about exams

The stated curriculum can be communicated to students or trainees in the form of learning objectives

(a) Superficial learning is motivated by a wish to complete a course and avoid failure. The process is characterised by rote learning and simple memorising of facts. The outcome is a superficial level of understanding.

(b) Deep learning is motivated by a wish to understand the subject. The process of achieving this objective varies but includes a logical stepby-step approach, with evaluation of evidence, linking of new with previous knowledge, use of analogies, and working out the relevance of the material for the student's present and future work.

(c) Strategic learning is motivated by a wish to do well in exams or to achieve promotion. The student who employs this approach will calculate whether deep or superficial learning will best suit the purpose in each instance.

Although some students are incorrigible superficial learners, most of us use all these approaches at different times and depending on the circumstances. This most effective approach has been called that of the 'versatile learner' (Newble \& Cannon, 1994) who seeks a deep level of understanding but also uses rote learning to establish a knowledge of the facts underpinning basic principles.

\section{Writing learning objectives}

\section{Keep it simple}

One mnemonic for writing learning objectives is CRAM: learning objectives should be clear, relevant, achievable and measurable.

(a) Clear - What is so familiar to teachers is new to students. It is worth letting another person have a look at the learning objectives before the students receive them. (b) Relevant-Although all of our work is relevant to the practice of psychiatry, not all of it is relevant to students who are studying a general course, whether as undergraduates or as junior doctors. Many of us find it difficult to reconcile our particular passion for, say, psychoanalysis, with the needs of the students. Think again. Do the students really need to know the details of the Freud-Klein controversies, or can it wait until they undertake psychotherapy training?

(c) Achievable - Think realistically. Do the students have the time and the resources to learn the material? Have I referenced an expensive book of which there is only one library copy for 300 students?

(d) Measurable - In medical training, where competence must be demonstrated, some kind of assessment is unavoidable and learning objectives offer a useful guide for students and teachers. Some knowledge or skills will be assessed in an examination; clinical skills and attitudes to patients and staff may be better assessed during clinical attachments.

\section{Think behaviourally}

What will the students have to do to show us that they have the knowledge or skill? Although the desired end-point may be to understand something, there has to be an intermediary step to demonstrate this understanding.

\section{Writing knowledge objectives}

People argue about how exactly learning objectives should be written, some demanding more specificity and some less (see Box 5). Behavioural words with little ambiguity have the virtue of clarity.

Words that are not very explicit and are more suitable for writing general goals rather than

Box 5. Words useful for writing knowledge objectives and which demonstrate understanding

Explain

Discuss (briefly / in detail)

Outline

Compare and contrast

Summarise 
learning objectives include 'understand', 'comprehend', 'be familiar with'. Other useful words, although needing a lower level of understanding, include: 'list', 'define', and 'draw a diagram to illustrate'. For example, if we want MRCPsych students to learn about attachment theory, the learning objectives may include:

- Outline the main points of Bowlby's theory of attachment.

- Explain the place of biological factors in the development of attachment behaviours in children.

- Describe the procedure for assessing attachment in infants, mentioning different classifications. Outline the research evidence which links these classifications with the child's future psychosocial development.

- Describe the instrument used to assess attachment status in adults, and discuss the relationship between parental attachment status and that of his or her child. Explain how this intergenerational link may be transmitted.

\section{Writing skills objectives}

Clinical skills are a key part of medical learning at all stages of our training. Skills-learning objectives may be written for a clinical attachment with or without an examination at the end of it. In postgraduate education, for example, they may be a useful part of the guidelines for both educational supervisor and trainee, to get a clear idea of what is expected of them during a sixmonth firm attachment (see Box 6).

Box 6. Writing skills objectives - example

By the end of the attachment, students will be able to:

Perform a mental state examination on a patient with a psychiatric illness

Assess suicide risk in a patient who has been admitted to hospital after self-injury

Explain the need for long-term medication to the family of a person with severe mental illness

Describe the procedure for admitting a patient under a section of the Mental Health Act 1983

Describe to a depressed patient the procedure for administering electroconvulsive therapy
Skills objectives may be skills to be performed, or they may be skills the student needs to know about but not necessarily perform personally. For example, a trainee may be expected to be able to administer electroconvulsive therapy and to describe the procedure to an examiner; an undergraduate may be required to have observed the procedure and be able to describe it.

When skills objectives are written, they should specify the skill and whether it is to be performed or described, and if performed, the conditions under which performance is to take place.

\section{Writing attitude objectives}

These are the hardest to write because they are so much less a specific skill and so much more a matter of personality. Having said that, it boils down to the fact that whatever a student's personal belief system, he or she is expected to behave in a professional way and we can lay down what these professional expectations are (see Box 7).

Doctors are free to dislike individuals, groups or lifestyles, but are expected to treat all their patients with courtesy and respect. They are also expected to treat colleagues with respect. Assessing this is not easy and although most of it is best done in the setting of clinical work, some aspects of attitudes towards patients can be assessed in examinations, for example, basic courtesies like introducing oneself and listening attentively to the patient.

Box 7. Writing attitude objectives: example

During the course of the attachment students will demonstrate an attitude of respect and courtesy to patients and colleagues. This will include:

Introducing him- or herself to patients, relatives and staff

Greeting patients by name whenever possible

Making appropriate eye contact when talking to a patient

Listening carefully to patients and relatives

Recognising a patient's anxiety and offering appropriate explanation and reassurance

Showing a willingness to learn from staff of all disciplines 


\section{Assessing learning objectives}

Assessing the achievement of knowledge objectives is relatively easy and usually done in written examinations. Although some skills objectives are assessed under examination conditions, skills and attitudes are often better assessed over a period of time and in a normal clinical setting by a more senior clinician. Continuous assessment also has the advantage of giving opportunity for early feedback so that a student has time to improve weaker areas.

\section{Essential, core and exceptional learning}

In medical undergraduate courses, learning objectives usually represent the core knowledge and skills that all students should acquire. If we want to reward outstanding knowledge outwith the core curriculum, we can offer an additional assessment for exceptional students and award prizes. In the prize examination the purpose of the assessment is not to demonstrate a doctor's safety or competence, but to reward excellence, so we can be more relaxed about straying from the straight and narrow of the stated curriculum (learning objectives) (see Box 8).

Learning objectives can be stratified, so that if teachers feel that some knowledge and skills are basic and should be well understood by all students, the pass mark can be much higher than the traditional $50 \%$. Course organisers may deem that certain critical skills or knowledge needed for safe practice must be performed adequately to pass an exam. For example, it may be an explicit requirement

Box 8. Essential learning, core learning and exceptional learning

Some learning objectives may be marked as essential learning which must be demonstrated to pass the examination, i.e. cannot be compensated

The pass mark may be different for different topics

Distinction or prize examinations may have a different standard outside the stated learning objectives that all students in 'finals' assess suicidal risk to a stated level of competence. Completion of the course may be delayed until this is satisfactorily demonstrated. The fact that students know that this will be assessed makes it likely that they will have mastered this essential clinical skill.

\section{Conclusions}

Many people have reservations about a very structured education system too firmly built upon examinations:

"At the best the means to an end, at the worst the end itself, they may be the best part of an education or the worst - they may be its very essence or its ruin' (Osler, 1913).

Most of us who have finished with exams still read for interest, but we tend to retain new information best if we have a task to compel us to organise our learning: a lecture, a paper, a clinical report that makes the reading particularly relevant. We select the main points, relate them to clinical examples, link them to related areas - in fact we engage in deep learning. This means that examinations are not intrinsically a bad thing, but that when we write our curricula we must show students that deep learning is expected and must ensure real understanding of the subject and not a simple recitation of facts stripped of meaning.

We devise curricula as a public statement of what students and trainees need to know or be able to do in order to be safe and competent doctors. Medical schools and Medical Royal Colleges are accountable to the public and to government, and curricula and examinations are, therefore, a public demonstration that students or trainees have reached a level of competence to practise. For this reason, if no other, it is likely that both published curricula and examinations will continue to be central in our medical education process. It is up to us to make sure that our curricula have clinical relevance and intellectual meaning and that they are defensible in the public arena - which brings us back to producing good learning objectives.

\section{References}

General Medical Council (1993) Tomorrow's Doctors: Recommendations on Undergraduate Medical Education. London: GMC.

Lowry, S. (1992) What's wrong with medical education in Britain? British Medical Journal, 305, 1277-1280.

- (1993) Teaching the teachers. British Medical Journal, 306, 127-130 
Newble, D. \& Cannon, R. (1994) A Handbook for Medical Teachers. London: Kluwer Academic.

Osler, W. (1913) Examinations, examiners and examinees. Lancet, 1047-1059.

Prideaux, D. J. (1992) Assessment of clinical competence in surgical students. Paper presented at the Fifth Ottawa Conference.

\section{Multiple choice questions}

1. Learning objectives:
a reduce student learning
b are a communication to students
c must always be formally assessed
d act as a check-list for student learning.

2. The lesson plan:
a is the same as the aim of the session
b structures a teaching session
c includes timing of components
d is only useful for small group teaching.

3. The stated curriculum:

a must be the same as the taught curriculum

b must include the assessed curriculum

c is a public statement about what doctors should know

$\mathrm{d}$ is a statement of core knowledge, skills and attitudes required of students.
4. Regarding types of learning:
a only deep learning is valuable
b deep learning promotes understanding
c superficial learning is often useful
d ambitious doctors use versatile learning.

5. Regarding essential, core and exceptional learning:

a exceptional students must lose out in a system which tests core learning objectives

b a special assessment can reward exceptional students

c performance of some skills may be mandatory to pass an examination

d examinations are antipathetic to deep learning.
MCQ answers

$\begin{array}{llllllllll}\text { 1 } & & \text { 2 } & & 3 & & 4 & & 5 \\ \text { a } & \text { F } & \text { a } & \text { F } & \text { a } & \text { F } & \text { a } & \text { F } & \text { a } & \text { F } \\ \text { b } & \text { T } & \text { b } & \text { T } & \text { b } & \text { T } & \text { b } & \text { T } & \text { b } & \text { T } \\ \text { c } & \text { F } & \text { c } & \text { T } & \text { c } & \text { T } & \text { c } & \text { T } & \text { c } & \text { T } \\ \text { d } & \text { T } & \text { d } & \text { F } & \text { d } & \text { T } & \text { d } & \text { T } & \text { d } & \text { F }\end{array}$

\section{New from Gaskell}

\section{Getting the Message Across}

\section{A review of research and theory about disseminating information in the NHS Claire Palmer and Julie Fenner}

An essential requirement of effective clinical practice is the rapid dissemination of research findings and their incorporation into practice. The usual dissemination method for NHS-generated research is publication in a professional journal and presentation at conferences. Occasionally educational strategies might be applied. There is increasing evidence that these strategies are often ineffective and that much of this new information is not adopted into practice for many years, if at all.

This book is aimed at all those in the long chain between the source of new information in the NHS (be it policy, research or managerial innovations) and its intended target audience. The book includes overviews of relevant research and theory to support the development of more effective dissemination strategies in the NHS.

\section{June 1999, Paperback, ISBN 190124236 6, £10.00}

Book Sales, Royal College of Psychiatrists, 17 Belgrave Square, London SW1X 8PG. Telephone +44 (0)171 2352351 ext. 146, fax +44 (0)171 2451231. Credit card orders can be taken over the telephone.

See the latest information on College publications on the Internet at: 